\title{
Ensuring LNG Liquefaction Facility's 'System Cleanliness': Pipe Air Blowing as a "Build It Clean" Attribute
}

\author{
Nirmal Surendran Menon \\ Associate Member, Institution of Mechanical Engineers (IMechE), Graduate Member, Engineering New Zealand \\ Email: nirmalsurendranmenon[at]gmail.com \\ Cell: +1(337)-965-4978
}

\begin{abstract}
Air Blowing is one of the most efficient methods of cleaning piping systems. In this technique a large-volume, clean system is selected as an air reservoir (a vessel or large-bore piping such as a reservoir header) and used to store dry air, which is then released into smaller open-ended piping systems where the velocity will significantly exceed the normal operational velocity, thus resulting in debris removal. This system of cleaning is used on sections of the LNG facility where it is necessary to keep the pipe-work dry, such as Propane, Mixed Refrigerant (MR), Natural Gas (NG) circuits and Instrument Air (IA) lines. It is also used on large bore systems where a sufficient flow of water is not possible. Air blowing in a LNG facility also serves the purpose of removing free water from the piping in order to prevent excessive use of gas for defrosting. In air blowing pipe-work, the objective is to maintain a high air velocity through the line for an extended period. To achieve this it is normal to include some large volume vessel (reactor, column, etc.) in the circuit to be blown. The circuit is then pressured up with air, and then rapidly vented out at an open end with the vessel in the circuit acting as an air reservoir to sustain the blow over a longer period. The velocity achieved during air blowing shall have the required drag force (preferably 1.1 to 1.5 times) higher than drag force during operation.
\end{abstract}

Keywords: Air Blowing, System Cleanliness, Build-It-Clean (BIC), Pre-Commissioning, LNG facility, Propane Refrigerant, Mixed Refrigerant, Natural Gas, Instrument Air, PFD (Process Flow Diagram)

\section{Introduction}

This article focuses on the application of air blowing to a LNG facility piping system that is best suited for pipe work that falls into the categories, that is required to be kept dry (i.e. Propane Refrigerant, Mixed Refrigerant, Instrument Air, Nitrogen, Lubricating Oil, Hot Oil, etc piping systems), whose system cannot be associated with being filled with water, that is fabricated from Stainless Steel and when insufficient low chloride water is available to support water flushing large diameter when the supply and containment/disposal of the volume of water required for flushing becomes impractical. Air Blowing shall be considered for all piping of 24 inches or less that requires cleaning in order to remove dirt \& debris as well as free water. Care must be taken not to subject the piping to extremely high velocities and choked flow as this has the potential to cause catastrophic failure of the piping due to flow induced vibrations. Typically this will occur at velocities greater than 0.84 Mach so it is recommended that 0.7 Mach is never exceeded. This can only be reliably controlled by restricting the upstream air pressure. Refer to Reservoir Pressure Limitations in Table A -1 below for more details. Direct Blowing of small bore piping is not affected by this provided the air supply is restricted to $58 \mathrm{psig}$.

\section{Air blowing techniques}

Two main techniques utilized when cleaning pipe work with air are Continuous Blowing and Rapid Decompression.

\section{A. Continuous Blowing}

In this method, dry compressed air is blown continuously from a source through the piping network being cleaned to atmosphere. This high velocity air stream dislodges and removes any rust, scale, dirt, foreign objects, etc that may be lodged within the pipe work being cleaned. This method is typically applied to small bore piping. A suitable supply source is selected, either from the utility air supply network or from a temporary compressor to a temporary storage vessel. A temporary hose from the supply source is connected directly to the piping to be blown and blown to atmosphere. The success of continuous air blowing is dependent upon ensuring the air generation system has sufficient capacity to develop the necessary cleaning air velocity.

\section{B. Rapid Decompression}

In this method the volume tank and piping network being cleaned is pressurized with dry compressed air from a source. At a selected pressure the air is released by either opening of a quick action blowing valve or rupture of rupture disc. The resultant rapid decompression results in a high velocity air stream which dislodges and removes any rust, scale, dirt, foreign objects, etc that may be lodged within the pipe work being cleaned. The valve or disc shall be located as close to the reservoir as possible to produce the maximum velocity within the pipe. The success of rapid decompression blowing is dependent upon locating a volume tank of adequate capacity at the start of the cleaning path. The volume tank is either a process vessel such as a reactor, column, knock out drum, etc or a special purpose rented volume tank. Volume tank capacity is the most significant factor affecting the length of time the pipe being cleaned is subjected to the target cleaning air velocity. For a given cleaning path the greater the capacity of the volume tank the less the number of blows required to achieve the target cleanliness criteria. Rate of decompression is another key factor affecting cleaning air velocity. Two main means of achieving a rapid decompression are typically utilized: (a) Where practical, a quick opening blowing valve arrangement shall be used, (b) Where a quick opening valve arrangement is not practical, rupture discs shall be used. If it is not feasible to place a valve upstream of the line being cleaned when performing the Air 
Accumulation Method then as a last resort, a knife valve or Rupture Disk may be installed on the discharge of the piping. The effectiveness of this blow set-up is poor and it is likely that this blow would have to be repeated multiple times before sufficient cleanliness is achieved.

\section{Initial Scavenging Run of Process Compressors}

For the pipe connected to the process compressors, air blowing is conducted with the process compressor operated with air or nitrogen (It is essential of course to investigate in advance whether or not the process compressors can be operated with air).

\section{Target Air Blowing}

Target Air Blowing will only apply to the small bore Compressor suction lines as well as gas turbine fuel gas lines of Carbon Steel Piping downstream of the inlet filter. Velocity calculations shall be applied in order to estimate the required upstream reservoir pressure required to produce a disturbance factor between 1.2 and 1.5. The target shall consist of white material, preferably paper mounted on a hard board, placed directly in the exhaust path of the line being blown. A gap of at least 1.5 pipe diameters is required between the exit point and the target so that it does not act as a restriction to the air flow. Blowing Density shall be calculated based on the upstream reservoir pressure using the following ideal gas equation:

Density $(\mathrm{kg} / \mathrm{m} 3)=$ Pressure $(\mathrm{Pa}) /\left[287.05 *\right.$ Temperature $\left.\left({ }^{\circ} \mathrm{K}\right)\right]$ $-\mathrm{A}$

Density $(\mathrm{lb} / \mathrm{ft} 3)=0.0624 \times \mathrm{A}$

The temperature shall be assumed to be $104^{\circ} \mathrm{F}$

Calculating the Reservoir Pressure shall be an iterative process by the following steps: (a)Calculate point to point line length of piping using isometric drawings or 3-D model, (b)Multiply by a factor of 1.3 to account for equivalent length of pipe fittings, (c)Carry out Isothermal Pressure Drop Calculation solving for Fluid Flow rate assuming an initial Inlet (Reservoir) Pressure of 2 psia and setting the Outlet Pressure as 14.5 psia, (d)From the calculation in (c), use the Mass Flow rate figure in the Disturbance Factor equation along with the calculated density, (e)Confirm DF is between 1.2 and 1.5, (f)If it is then a reservoir pressure of 29 psia is acceptable, (g)If it is below 1.2 then repeat steps (c), (d) and (e) using a higher reservoir pressure, if it is above 1.5 then repeat steps (c), (d) and (e) using a lower reservoir pressure. Operating data shall be taken from PFDs if possible but supplementary information from a datasheet for a control valve in the line may prove a more likely source of accurate information. If no information is available then compressor vendor shall specify the operating flow rate and density.

\section{Air requirements}

Air supplied for cleaning of pipe work shall be oil free and dried to a dew point $<14^{\circ} \mathrm{F}$. Typically a portable oil free air compressor and heater less drier skid are utilized to generate the dry air for pipe work cleaning. The effectiveness of using air to clean pipe work is dependent upon generating sufficient cleaning forces (air velocities) at the wall of the pipe being cleaned. For pipe work normally in gas service the cleaning air velocity shall be the greater of $1.3 \mathrm{x}$ normal flow rate or $132 \mathrm{ft} / \mathrm{s}$ (for pipe work normally in liquid service the cleaning air velocity shall be in the range 66 to $132 \mathrm{ft} / \mathrm{s}$ ). The capacity of commercially available portable air compression/drier systems is normally adequate to support the cleaning of pipe work up to 4 inch diameter using the continuous blowing technique. Pipe work greater than 6" diameter shall be subject to cleaning with air utilizing rapid decompression.

\section{Tools and equipment required for carrying out air-blowing}

\section{A. $\quad$ Fast Acting Knife Valves}

The air blowing shall commence when the valve directly upstream of the line being cleaned (known as the air blow valve) is fully opened. The maximum blow flow rate possible occurs when the air blow valve is $100 \%$ open and the upstream reservoir pressure is at its maximum. During the period of time it takes to open the air blow valve fully, the reservoir starts depressurizing and loses an initial mass of air which affects the initial air blow flow rate. It is therefore imperative that the air blow valve is opened in the shortest time possible and it is recommended that this time period is less than 0.5 seconds. For some air blows it may be more practical to utilize permanent in-line valves. However, if a permanent valve is to be used as the air blow valve it must be confirmed that it can be opened quickly (less than 0.5 seconds) and that the line upstream of the valve has been confirmed as clean so that it is not damaged during the blow. When procuring Knife Valves for air blowing, it is recommended that a minimum of 1 per line size in the range of 3 inches up to 24 inches rated for 150\# are purchased. For the larger valves, actuators should also be purchased that allow the valves to be opened in less than 0.5 seconds.

\section{B. Adequately Sized Reservoir}

As the reservoir pressure must be limited to protect the downstream piping, and the opening of the air-blow valve is not considered to be instantaneous, the size of the reservoir being utilized becomes critical. For example, if a 24 inches $(600 \mathrm{~mm})$ line is being blown using a very small reservoir at 20.3053 psia (1.4 bara) then there is the possibility that the reservoir will have discharged completely by the time the valve has been opened fully. A suitable reservoir size can be calculated based on an allowable change in air density in the reservoir during the time it takes to fully open the air blow valve. The following assumptions have been made:

Air Blow Temperature $=104^{\circ} \mathrm{F}\left(40^{\circ} \mathrm{C}\right)$, Knife Valve opens in $<5 \mathrm{~s}$, Allowable $\Delta \mathrm{P}$ in Reservoir while valve opens fully = $5 \%$. Worst case scenario is the Maximum Mach case for each of the scenarios shown in the max allowable reservoir pressure in Table $\mathrm{A}-1$.

\section{Density Calculation:}

$\Delta$ Density $\left(\mathrm{kg} / \mathrm{m}^{3}\right)=\Delta$ Pressure $(\mathrm{Pa}) /[287.05 *$ Temperature $\left.\left({ }^{\circ} \mathrm{K}\right)\right]-$ Eq. 1 $\Delta$ Density $\left(\mathrm{lb} / \mathrm{ft}^{3}\right)=0.0624 \times \mathrm{Eq} .1$

Volume Calculation:

Volume $\left(\mathrm{m}^{3}\right)=$ Flowrate $(\mathrm{kg} / \mathrm{s}) \times$ Valve opening time $(\mathrm{s}) /$ $\Delta$ Density $\left(\mathrm{kg} / \mathrm{m}^{3}\right)-$ Eq. 2 


\section{International Journal of Science and Research (IJSR)}

Index Copernicus Value (2016): 79.57 | Impact Factor (2018): 7.426

Volume $\left(\mathrm{ft}^{3}\right)=35.31 \times$ Eq. 2

A summary of the results are given in the Table A - 2

For the 16 inches $(400 \mathrm{~mm})$ to 24 inches $(600 \mathrm{~mm})$ piping the recommended reservoir volumes are considered large and finding a suitable vessel may be difficult. As a minimum the reservoir shall be rated for 145.038 psia (10bara) and shall be equipped with adequately sized relief valves. It may be possible to use a vessel within a module as the reservoir before the vessel internals are installed provided that it is adequately rated, has relief valves protecting it and has been tightness tested prior to use.

\section{Air Compressor}

Low Pressure 145.038 psig (10barg) oil-free air compressor (1500scfm) with heatless dryer package \& dust filers (supplying air with a dew point of $-40^{\circ} \mathrm{F}$ ). Provision of a standby compressor shall be considered. To connect the compressor to the reservoir various rubber flexi hoses fitted with 150\# CS end flanges shall be used.

\section{Pressure Gauge}

A Pressure Gauge shall be connected to the reservoir prior to the introduction of air from the compressor. The pressure gauge shall be fit for purpose, i.e. for air blows with a low max allowable reservoir pressure a gauge with a low maximum shall be used. It is recommended that, as a minimum, pressure gauges are provided with the following ranges:

$0-23$ psig

$0-36$ psig

$0-145$ psig

\section{Pneumatic blow calculations}

The concept of cleaning force ratio (CFR) momentum calculation provide a method for understanding when velocity and flow conditions have the most chance for dislodging contaminates and moving them through the piping system.

\section{A. Cleaning Force Ratio (CFR) or Momentum Ratio Calculations}

Line blowing effectiveness has been identified to be a function of the cleaning force ratio (CFR) momentum that is achieved. Cleaning force momentum is the product of mass flow and velocity that interacts aerodynamically with particulates extending beyond the pipe wall into the moving fluid at the fluid boundary. It is the goal of the cleaning process to pass a fluid (gaseous air or nitrogen) through the piping system with higher cleaning forces than would ever be achieved from the flow of fuel gas through the pipe during peak plant operations. A CFR of greater than one ensures that the momentum achieved during cleaning will exceed the momentum that can be expected during operations. Some turbine manufacturers have provided recommended CFRs of as much as 2. The presumption is that all or nearly all particles remaining attached to the pipe walls after pneumatic blows are unlikely to be dislodged during operations. The cleaning force momentum ratio calculation is shown below in equation. It is calculated by taking the mass flow squared times the specific volume of the fuel gas as it will flow during maximum operating conditions. That value is the denominator in the momentum ratio fraction. The numerator is the product of mass flow and specific volume of the cleaning medium during blow conditions. The target or ideal CFR has been identified as having a value of between 1.2 and 2.0.

The following formula represents the calculation described above:

$$
\mathrm{CFR}=\left[\mathrm{M}(\text { blow })^{2} \mathrm{x} \mathrm{V}(\text { Blow })\right] /\left[\mathrm{M}(\text { ref })^{2} \mathrm{x} \mathrm{V}(\text { ref })\right]
$$

$\mathrm{M}$ (blow) = Mass flow of medium used for blowing (Air), $\mathrm{lbm} / \mathrm{sec}(\mathrm{kg} / \mathrm{s}) \mathrm{V}($ blow $)=$ Specific volume of blow medium (Air) during the blow, ft $3 / \mathrm{lbm}(\mathrm{m} 3 / \mathrm{kg}) \mathrm{M}(\mathrm{ref})=$ Mass flow of Natural gas under maximum load conditions $\mathrm{lbm} / \mathrm{sec}(\mathrm{kg} / \mathrm{s})$ $\mathrm{V}($ ref $)=$ Specific volume of Natural gas under lowest possible pressure to achieve the maximum flow conditions, $\mathrm{ft} 3 / \mathrm{lbm}(\mathrm{m} 3 / \mathrm{kg})$

\section{Items to be spooled out prior to air blowing}

Prior to air blowing, as a minimum, safety valves as required (usually not required), Check valves (as required), Rupture disks, Orifice plates or flow meter elements, In line mixers/In-line strainers Inline Butterfly Valves, Spray nozzles, Analyser probe, Control valves, Self-actuated control valves, Tight shut off (TSO) valve, Chemical injection probes shall be removed and spooled out. Where an in-line instrument is to be spooled out, a spool piece designed to the specification of the line it is to be installed in shall be used. If the exit point of the air blow is considered a dangerous location to personnel and / or permanent plant equipment, temporary spool pieces shall be used to or an engineered deflector pipe shall be installed to route the air exit point to a safe location (Figure B -1 ). Any spool pieces required shall be identified and specified in the Method statement. A full set of spare gaskets for all piping sizes shall be made available. A set of spades, rated for the system being blown, shall be made available for isolating connecting systems that must not be pressurized.

\section{Define blow paths}

A set of blow packs shall be created for each system where a particular line has been identified as requiring cleaning by Air Blowing Method. The latest "Master" P\&IDs shall be used to mark-up each blow path. Multiple blows can be shown on each P\&ID and the lines being cleaned shall be clearly identified. Where possible, blow path shall be ensured as per normal operational direction. Main Header(s) shall be cleaned first prior to blowing subsequent branch lines. Instruments and in-line fittings to be removed, flanges to be spaded off, spool pieces to be fabricated, blow discharge point(s) and the location of the air blow shall be highlighted. State whether or not the air-blow valve will be a temporary installed knife /fast acting valve or if a permanent valve is to be used. If it is the latter then assurances must be made to confirm that the valve can open immediately ( $100 \%$ open in $<0.5 \mathrm{~s})$ i.e. is not geared, or will not be damaged during the air blowing activity. Air blow reservoir shall be protected by a suitably rated Pressure Relief Valve when connected to an operational compressor. The maximum Reservoir Pressure that shall be used for the blow using shall be as per Table A -1 for standard air blows or as calculated for Target Air Blows. Reservoir volume shall be confirmed as adequate using Table $\mathrm{A}-2$ as a guide. 


\section{Blowing}

Reservoir pressure shall be increased to $25 \%$ of max allowable reservoir pressure, then air supply shall be cut off and compressor isolated. Quick acting air blow valve shall be opened as quickly as possible and reservoir shall be allowed to discharge completely. Discharge piping shall be monitored for signs of flow induced vibrations and discharged effluent shall be monitored at exit point. Reservoir pressure shall be confirmed to be 0 psig and that there is no audible sign of air exiting the piping. Repeat steps above at 50\%, $75 \%$ and $100 \%$ of max allowable reservoir pressure. NOTE: NEVER TAKE THE RESERVOIR PRESSURE ABOVE THE MAXIMUM ALLOWABLE. If exit point shows signs of excessive vibration, reduce pressure by 3 psi for the next blow and maintain all subsequent blows at that pressure. Continue blowing at the maximum pressure until there are no signs of debris or water being discharged at the exit point. For Target Blowing, perform one final blow at maximum reservoir pressure with white paper mounted on a hard backing positioned in the air exhaust path at a minimum distance of 1.5 pipe diameters. A typical air blowing setup line diagram is shown in Figure B -1 .

\section{Acceptance criteria}

The Acceptance Criteria for standard Air Blowing is No visible signs of free water debris or rust at the blow point at the maximum allowable reservoir pressure and for target air blowing is "White Paper Test". No discoloration or particles visible on a sheet of white paper, mounted on a hard backing, positioned in the air exhaust path at a minimum distance of 1.5 pipe diameters. Also a post air blow boroscoping shall also determine the acceptability criteria of the Air Blow.

\section{Conclusion}

Air blowing of pipelines is extremely important for critical service lines such as compressor suction lines and achieving cleanliness of these critical pipelines for the system to be commissioned plays an important factor during commissioning and subsequent start up of the system.

Reference to this paper should be made as follows: Surendran Menon, N., (2019) 'Ensuring LNG liquefaction facility's 'system cleanliness': 'Pipe Air Blowing as a "BUILD IT CLEAN" attribute'.

\section{References}

[1] T.K. Jack, A Simplified Pipeline Calculations Program: Liquid Flow (1) ॥, International Journal of Scientific \& Engineering Research

[2] C.L. Yaws, Physical Properties, McGraw Hill, 1977

[3] Aligna Graphics Co., Pipeline Sizing Program, Pipedi User Manual, 1998

[4] J.B. Evett, 2500 Solved Problems in Fluid Mechanics and Hydraulics, McGraw-Hill, 1989

[5] Esposito, Fluid Power with Applications, Prentice Hall, 1980

[6] R.N. Fox, Introduction to Fluid Mechanics, Wiley, 1992.

[7] R.W. Miller, Flow Measurement Engineering Handbook, McGraw-Hill, 1985

[8] R.H. Perry, and D.W. Green, (eds), Perry's Chemical Engineers' Handbook, 6th edn., McGraw-Hill, 1984

[9] V.L. Streeter, Fluid Mechanics, McGraw-Hill, 1983

\section{Author Profile}

Nirmal Surendran Menon received his Bachelor of Engineering in Mechanical from Anna University, Tamil $\mathrm{Nadu}$, India in 2005 and Master of Science in Project Management from National University of Singapore in 2010. $\mathrm{He}$ has more than 12 years of experience in EPC projects in the Oil/Gas/Petrochemical sector. He is currently working as Field Engineer in an LNG Liquefaction Project in South West Louisiana, US. His interests include pipeline system integrity, pipeline system cleanliness, Loss Prevention in LNG liquefaction facilities as part of project execution.

Table A - 1:

\begin{tabular}{|c|c|c|c|c|c|}
\hline \multirow{2}{*}{\multicolumn{2}{|c|}{ Equivalent Pipe Length ( $\mathrm{ft}$ ) }} & \multicolumn{4}{|c|}{ Max Allowable Reservoir Pressure (psig) } \\
\hline & & $164-820 \mathrm{ft}$ & $824-1641 \mathrm{ft}$ & $1644-3281 \mathrm{ft}$ & $>3281 \mathrm{ft}$ \\
\hline \multirow{9}{*}{ 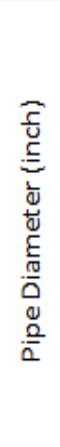 } & \multirow{3}{*}{$3-6$ inch } & 14.5 & 43.5 & 65.3 & 94.3 \\
\hline & & Mach $_{\min }=0.187$ & $\operatorname{Mach}_{\min }=0.299$ & $\operatorname{Mach}_{\min }=0.297$ & $\operatorname{Mach}_{\min }=\mathrm{n} / \mathrm{a}$ \\
\hline & & Mach $_{\max }=0.580$ & Mach $_{\max }=0.622$ & Mach $_{\max }=0.627$ & Mach $_{\max }=0.618$ \\
\hline & \multirow{3}{*}{$8-14$ inch } & 10.15 & 29 & 36.25 & 58.02 \\
\hline & & Mach $_{\min }=0.264$ & Mach $_{\min }=0.386$ & $\operatorname{Mach}_{\min }=0.327$ & $\operatorname{Mach}_{\min }=\mathrm{n} / \mathrm{a}$ \\
\hline & & Mach $_{\max }=0.671$ & Mach $_{\max }=0.693$ & $\operatorname{Mach}_{\max }=0.605$ & $\operatorname{Mach}_{\max }=0.639$ \\
\hline & \multirow{3}{*}{$16-24$ inch } & 5.8 & 15.95 & 23.3 & 40.61 \\
\hline & & $\operatorname{Mach}_{\min }=0.274$ & $\operatorname{Mach}_{\min }=0.366$ & $\operatorname{Mach}_{\min }=0.341$ & $\mathrm{Mach}_{\min }=\mathrm{n} / \mathrm{a}$ \\
\hline & & Mach $_{\max }=0.642$ & Mach $_{\max }=0.614$ & $\operatorname{Mach}_{\max }=0.589$ & Mach $_{\max }=0.617$ \\
\hline
\end{tabular}

Volume 8 Issue 1, January 2019 www.jijsr.net 
International Journal of Science and Research (IJSR)

ISSN: 2319-7064

Index Copernicus Value (2016): 79.57 | Impact Factor (2018): 7.426

Table A - 2

\begin{tabular}{|c|c|c|c|c|c|c|}
\hline \multicolumn{3}{|c|}{ Equivalent pipe Length ( $\mathrm{ft}$ ) } & $164-820 \mathrm{ft}$ & $823-1640 \mathrm{ft}$ & $1644-3281 \mathrm{ft}$ & $>3281 \mathrm{ft}$ \\
\hline \multirow{9}{*}{ 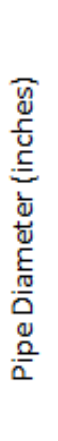 } & \multirow{3}{*}{$3-6$ inches } & Pressure (psig) & 14.5038 & 43.511 & 65.267 & 94.275 \\
\hline & & Flowrate (lb/hr) & 33951.188 & 36376.273 & 36596.736 & 36155.81 \\
\hline & & Volume $\left(\mathrm{ft}^{3}\right)$ & 670.979 & 353.147 & 282.517 & 176.573 \\
\hline & \multirow{3}{*}{$8-14$ inches } & Pressure (psig) & 10.153 & 29 & 36.259 & 58.0151 \\
\hline & & Flowrate $(\mathrm{lb} / \mathrm{hr})$ & 187392.92 & 192904.48 & 168653.63 & 177924.1 \\
\hline & & Volume $\left(\mathrm{ft}^{3}\right)$ & 4414.33 & 2577.97 & 1942.31 & 1412.59 \\
\hline & \multirow{3}{*}{$16-24$ inches } & Pressure (psig) & 5.801 & 15.954 & 23.206 & 40.611 \\
\hline & & Flowrate $(\mathrm{lb} / \mathrm{hr})$ & 551155.66 & 529109.429 & 507063.203 & 529109.4 \\
\hline & & Volume $\left(\mathrm{ft}^{3}\right)$ & 15750.3 & 10064.7 & 7804.54 & 5579.72 \\
\hline
\end{tabular}

Figure B - 1

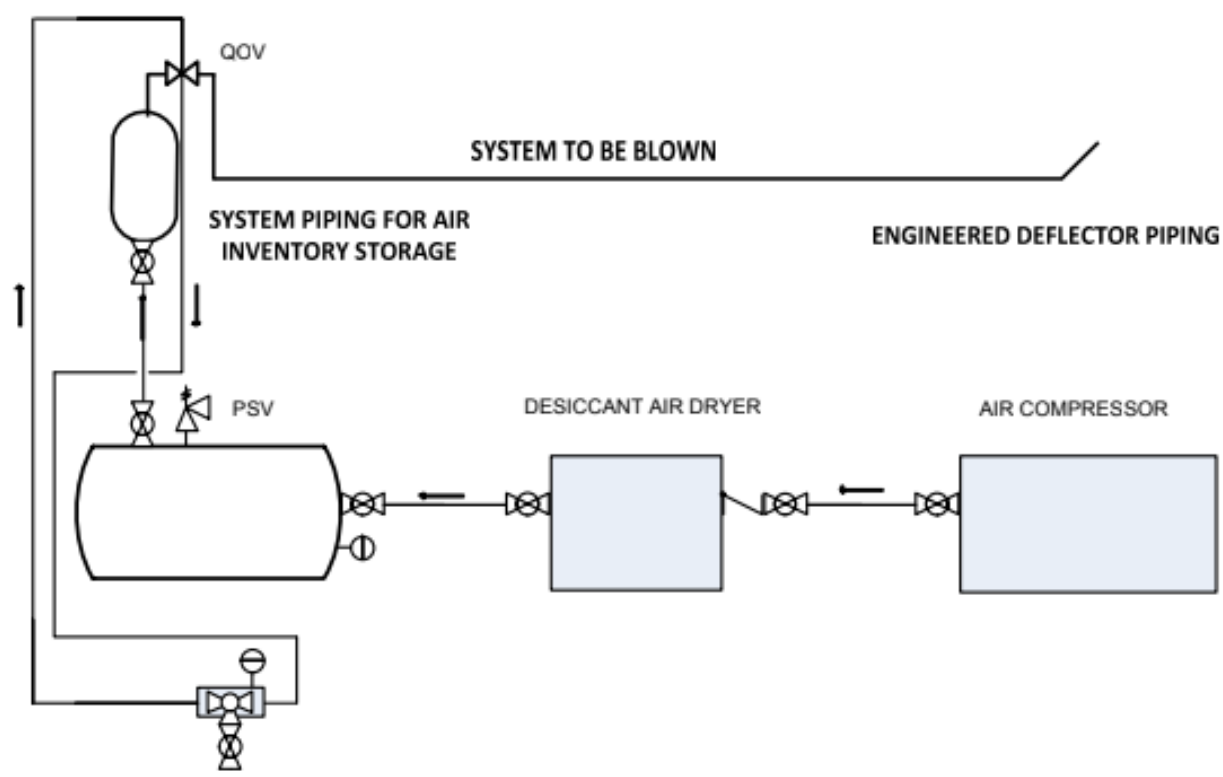

KNIFE GATE VALVE

CONTROLLER (IF REQUIRED) 